\title{
Impact of out-of-class science and engineering activities on physics identity and career intentions
}

\author{
Robynne M. Lock $\odot,{ }^{1}$ Zahra Hazari, ${ }^{2,3,4}$ and Geoff Potvin ${ }^{3,4}$ \\ ${ }^{1}$ Department of Physics \& Astronomy, Texas A\&M University-Commerce, Commerce, Texas 75429, USA \\ ${ }^{2}$ Department of Teaching \& Learning, Florida International University, Miami, Florida 33199, USA \\ ${ }^{3}$ STEM Transformation Institute, Florida International University, Miami, Florida 33199, USA \\ ${ }^{4}$ Department of Physics, Florida International University, Miami, Florida 33199, USA
}

(Received 7 May 2019; published 17 October 2019)

\begin{abstract}
The number of physics bachelor's degrees that are awarded in the United States annually is small compared to most other science, technology, engineering, and mathematics fields, and only about one-fifth of these degrees are awarded to women. Understanding the influence of students' science and engineering experiences on career choices is critical in order to improve future efforts to increase the number of physics majors and the participation of women. In this work, we use a physics identity framework to examine the impact of out-of-class science and engineering activities on three identity dimensions and the relationship between these dimensions and physics career choice. Through structural equation modeling of survey data from 5541 college students, we find that out-of-class science and engineering activities have the largest influence on physics performance/competence beliefs, but the association of performance/competence beliefs to overall physics identity and physics career choice is primarily mediated through recognition beliefs and physics interests. Furthermore, out-of-class science and engineering activities have a larger effect on recognition beliefs for men than for women, which is a challenging finding in light of the fact that recognition beliefs are the most influential identity dimension for women. The results of this work begin to highlight the need for out-of-class science and engineering activities that focus on not only enhancing students' performance/competence beliefs but also students' interests, particularly those students not previously interested, and women's recognition beliefs with respect to physics.
\end{abstract}

DOI: 10.1103/PhysRevPhysEducRes.15.020137

\section{INTRODUCTION}

In order to remain both innovative and competitive, the United States requires more science, technology, engineering, and mathematics (STEM) degree holders [1]. Supporting physics education is an important component of this effort, as physicists have led the development of many new technologies that have impacted modern society, such as lasers and liquid crystal displays (LCDs) $[2,3]$. Encouragingly, the number of physics bachelor's degrees earned nationwide has recently reached an alltime high of over 8000 [4]. However, this remains a small fraction of all STEM degrees awarded, as a majority of STEM degrees are in the areas of engineering and biological sciences [5]. Furthermore, the representation of women in physics remains consistently low, with the percentage of physics bachelor's degrees earned by

Published by the American Physical Society under the terms of the Creative Commons Attribution 4.0 International license. Further distribution of this work must maintain attribution to the author(s) and the published article's title, journal citation, and DOI. women stagnating at approximately $20 \%$ for more than a decade [6]. If women do not pursue physics at a greater rate, the community will continue to lose out on a substantial part of the talent pool. All genders should have equal opportunity and support in pursuing physics. As a step to addressing these problems, students' experiences with physics and the impact on their career decisions should be critically examined. This includes both in-class and out-of-class experiences that students have before making their college and career decisions. These experiences may impact young women and men differently as the cultural and social context of these experiences may convey different messages and support young women differently than men. In prior work, we examined the effects of in-class high school physics experiences on students' physics identities and career choices [7-10], and, in this paper, we examine the impact of out-of-class science and engineering (OCSE) activities, with attention to possible differential impacts on women. OCSE activities are a specific subset of out-of-school time (OST) activities. We use a physics identity framework to understand how students make their career decisions and, using this framework, examine the impact of OCSE activities on students' physics career intentions. 


\section{BACKGROUND}

Students spend the majority of their lives outside of class, so understanding the impact of OCSE activities on physics identity and career choice may lead to significantly greater insight. OCSE activities occur in various informal learning environments. These environments include programmed settings, everyday experiences, and designed settings [11]. Programmed settings include summer camps and after school programs; everyday experiences include reading about science or engaging in science-related hobbies; while designed settings include museums and zoos [11]. In this paper, we focus on programmed settings and everyday experiences.

The impacts of programmed settings on students' attitudes towards science have been studied more frequently than those of everyday experiences. These include science fairs, clubs, and summer programs and camps. Science fair experiences have been found to have positive impacts on STEM career interests [12], and students have reported that science fairs are fun and provide opportunities to learn new things $[13,14]$. Participation in STEM clubs has been associated with STEM career interests [12,15]. Furthermore, summer programs and camps for middle school and high school students have been found to result in increased motivation, confidence, and attitudes towards science and science careers $[16,17]$.

While a number of positive outcomes have been documented, the nature of STEM programs needs to be examined to understand the effects on students' experiences and perceptions. One case study of a student showed how participating in a science fair and a robotics tournament contributed to the student's disciplinary identity development in physics by increasing their agency in physics [18]. This student's teacher supported and encouraged him giving him full ownership of his project and recognizing him as an expert in the classroom. However, if students are required to participate in science fairs and are not provided adequate support, they may not have positive experiences with science and may perceive science negatively. This is often the case as science fair participation is most often nonvoluntary, and teachers typically provide minimal support to students in their investigations [19]. The support and encouragement students receive in noncompetitive environments also impacts outcomes. In one university program, high school students were hired as researchers to assist in improving science education in urban schools. Three of these student researchers were found to build science identity when they were empowered to use rap to explain science [20]. They were encouraged to bring other areas of their lives in which they were experts into the world of science. Thus, OCSE activities in programmed settings may provide opportunities for physics identity development when activities promote student agency, i.e., students acting in their own world in intentional, self-driven ways. Therefore, activities such as participating in STEM clubs, summer programs, and camps may play an important role in encouraging students to pursue science careers.

The effectiveness of OCSE activities in programmed settings for increasing the representation of women in STEM needs to be explored further. In prior work, boys and girls were found to participate in OCSE activities (such as STEM clubs and competitions) at approximately the same rate, and both boys and girls were reported to have similar increases in STEM career interests from these activities [15]. However, in the specific case of science fairs, young men ranked "competing against others" as a more valuable outcome than young women, while young women ranked "being on a team" as a more valuable outcome than young men [13]. Thus, science fairs may benefit all genders, but the specific impacts on young women and men's attitudes and career choices may differ. Furthermore, Simpkins et al. hypothesize that while young men and women participate in these activities at similar rates overall, more young men participate in physical science-related activities while more young women participate in life science-related activities [21]. The distinction between effects on career interests in different fields of STEM thus needs to be examined. If Simpkins et al. are correct, women may experience more positive impacts on biology career interest, and men may experience more positive impacts on physical science career interest.

Compared to programmed settings, the effect of everyday science activities has been studied to a lesser extent. Several of these activities have been shown to relate to positive outcomes. For example, reading or watching either science fiction or nonfiction science has been found to predict STEM career choice [15], while reading science books and other activities such as collecting rocks or insects predict self-concept, interest, and the perceived importance of math and science [21]. These factors in turn predict students taking more science classes at the high school level [21]. Unlike in programmed settings where men and women have been reported to participate equally, engagement in everyday science activities varies by gender. Men report reading or watching science fiction or nonfiction science to a greater extent than women do [15]. Furthermore, even among professional scientists, men have reported participating in more self-initiated science activities than women have [22]. For activities taking place at home, the influence of parents becomes especially important. Parents have been found to give boys more detailed explanations of science than girls [11]. Hence, while everyday science activities relate to STEM careers, men and women experience them in different amounts and likely also experience them differently.

Despite having evidence for the positive effects of both structured and unstructured informal learning 
environments on STEM career related outcomes in general, little work has been done to study the specific effects on physics identity or physics career choice. Since physics accounts for only a small percentage of STEM graduates, the connection between OCSE activities and physics identity and the potential impact on the underrepresentation of women needs to be examined.

\section{THEORETICAL FRAMEWORK}

We draw on the physics identity framework used by Hazari et al. [7], which builds on the framework developed by Carlone and Johnson [23]. Carlone and Johnson's science identity framework for practicing scientists consists of three dimensions: recognition beliefs, performance (of scientific practices), and competence (knowledge and understanding of science content) [23]. Hazari et al. adapted this framework when defining physics identity for students by focusing on more internalized versions of Carlone and Johnson's dimensions and adding the dimension of interest [7]. In Carlone and Johnson's framework, the dimensions fully constitute science identity and juxtapose performances (actions demonstrating competence) and beliefs (feelings of recognition by self and others). In Hazari et al.'s framework, the four dimensions shape physics identity, where identity is an internal construct based on how individuals see themselves, which is fundamentally shaped by society and culture. This is in contrast to the former in which identity is constantly negotiated between the individual and society and culture. We use physics identity as defined by Hazari et al. because this framework allows for clearer modeling of possible influences on identity and the influence of physics identity on career outcomes [7]. Hence, while Carlone and Johnson included self-recognition within recognition beliefs [23], Hazari et al. defined recognition beliefs as only beliefs about recognition by others, and used self-recognition as an overall indicator of physics identity that is shaped by the identity dimensions [7]. Overall, we define physics identity as the extent to which students believe themselves to be a "physics person," while recognition beliefs can be described as the extent to which a student perceives that parents, teachers, and peers see them as a physics person. Performance beliefs are a student's beliefs in their ability to perform physics-related tasks (as opposed to their actual performances or actions), while competence beliefs are a student's beliefs in their ability to understand physics (rather than their ontological competence). Finally, interest represents a student's desire to learn more about physics. Performance/competence beliefs have been found to be quantitatively indistinguishable for students at the end of high school and the beginning of college [7,9,24].

Although the meanings of interest and performance/ competence are relatively straightforward, the meaning of being a physics person varies between individuals as do the actions that can cause individuals to perceive others as seeing them as a physics person [25]. According to a case study of high school physics classrooms, forms of recognition have been found to include setting high expectations and giving challenging assignments while at the same time providing students with the necessary support to meet those expectations and challenges [25]. Another form of recognition has been found to create a classroom environment that provides opportunities for students to take on leadership roles and demonstrate their expertise $[10,25]$. Finally, teachers demonstrating to students that they care and that they are willing to invest time in their students is a way of showing that they believe that their students can do difficult work [25].

Science identity has been used to understand the career trajectories of professional scientists [23], and physics identity has been found to predict physics career choice for college students [7]. This framework extends to other disciplines as well. Physics identity and math identity also predict engineering career choice for college students [8]. Furthermore, drawing on data from a similar population, previous work in mathematics identity developed a model demonstrating that recognition beliefs, interest, and performance/competence beliefs are related to but distinct from the overall indicator of identity [26]. We seek to establish the relationship between the three dimensions of physics identity and overall physics identity for a general population of college students. We hypothesize that the relationships for physics identity will be the same as those for mathematics identity for this population of students. However, in this work we extend the model to also include the connection between overall physics identity and physics career choice as found in prior work [7]. We note that discipline-based identities are only parts of students' broader personal and social identities [27].

In previous work, we found that men were more likely to have stronger physics identities than women and that recognition beliefs have a larger effect on women's identities and career intentions than on men's [9]. In this work, we examine the relationships between these dimensions and students' overall physics identity (considering potential distinctions in these relationships for women) and, going further than in previous work, we examine the effect of OCSE activities on each of the physics identity dimensions and, in turn, on physics career choice. Our analytic approach is structural equation modeling.

\section{METHODS}

\section{A. Data source}

The data used in this work are drawn from the Sustainability and Gender in Engineering (SaGE) project. The SaGE survey was distributed to a nationally 
TABLE I. Wilcoxon tests for out-of-class science and engineering activities items.***: $p<0.001$.

\begin{tabular}{|c|c|c|c|c|c|c|c|c|}
\hline \multirow[b]{2}{*}{ Item } & \multirow[b]{2}{*}{ Item description } & \multicolumn{3}{|c|}{ Female } & \multicolumn{3}{|c|}{ Male } & \multirow[b]{2}{*}{ Sig. } \\
\hline & & Mean & SE & Median & Mean & SE & Median & \\
\hline Q21a & $\begin{array}{l}\text { Participated in science/engineering clubs, camps, } \\
\text { or competitions }\end{array}$ & 0.583 & 0.019 & 0 & 0.766 & 0.024 & 0 & $* * *$ \\
\hline Q21d & Participated in other science/engineering hobbies & 0.713 & 0.021 & 0 & 1.305 & 0.030 & 1 & $* * *$ \\
\hline Q21e & $\begin{array}{l}\text { Read/watched science/engineering programs } \\
\text { or literature }\end{array}$ & 1.451 & 0.028 & 1 & 2.029 & 0.034 & 2 & $* * *$ \\
\hline Q21g & $\begin{array}{l}\text { Presented or gave a poster on science/engineering } \\
\text { content }\end{array}$ & 0.963 & 0.024 & 0 & 1.209 & 0.028 & 1 & $* * *$ \\
\hline Q21h & $\begin{array}{l}\text { Explained science/engineering topics to experts } \\
\text { (e.g., professionals/teachers) }\end{array}$ & 0.437 & 0.017 & 0 & 0.741 & 0.024 & 0 & $* * *$ \\
\hline Q21i & $\begin{array}{l}\text { Explained science/engineering topics to nonexperts } \\
\text { (e.g., relatives, peers) }\end{array}$ & 1.086 & 0.026 & 0 & 1.625 & 0.033 & 1 & $* * *$ \\
\hline
\end{tabular}

representative, stratified, random sample of 50 colleges and universities during Fall 2011 [28]. The institutional response rate was $100 \%$; that is, all 50 recruited institutions returned completed surveys. In total, 6772 students completed surveys representing at least a $40 \%$ response rate, as measured by the number of surveys returned against the number that were mailed to each institution (the latter was intentionally estimated high, so $40 \%$ represents a lower bound on the actual response rate). The 47 multi-item questions appearing on the survey focused on several areas including students' career intentions, high school math and science experiences, OCSE activities, sustainability beliefs, and demographics. Many items were adapted from previous surveys, including the Persistence Research in Science and Engineering (PRiSE) project [7]. Focus groups and pilot testing with first-year engineering students at two four-year universities were used to establish face and content validity. To establish reliability (stability of survey items), a test-retest study was conducted with 62 college students. Analysis of the items appearing in this paper showed acceptable stability: for the 18 items used in this paper, the average test-retest correlation was 0.739 , with all items falling in the range $(0.515,0.857)$. The final survey was administered in regular-stream, introductory English courses so that a broad cross section of students representing a wide spectrum of interests in STEM could complete the survey.

The current paper focuses on items about OCSE activities, physics identity, and physics career intentions. These items and their descriptive statistics are shown in Tables I-III, respectively, along with the statistical significance of the differences between males and females calculated using Wilcoxon rank sum tests. The out-of-class science activities items responses are "Never in my life," "1-2 times," "3-4 times," "5-6 times," and "More than 6 times in my life." For the calculation of descriptive statistics shown in Table I,

TABLE II. Wilcoxon tests for physics identity items. ***: $p<0.001$.

\begin{tabular}{|c|c|c|c|c|c|c|c|c|}
\hline \multirow[b]{2}{*}{ Item } & \multirow[b]{2}{*}{ Item Description } & \multicolumn{3}{|c|}{ Female } & \multicolumn{3}{|c|}{ Male } & \multirow[b]{2}{*}{ Sig. } \\
\hline & & Mean & SE & Median & Mean & SE & Median & \\
\hline Q27Phys_a & I see myself as a [physics] person & 0.922 & 0.025 & 0 & 1.604 & 0.032 & 2 & $* * *$ \\
\hline Q27Phys_b & $\begin{array}{l}\text { My parents/relatives/friends see me as a [physics] } \\
\text { person }\end{array}$ & 0.906 & 0.025 & 0 & 1.550 & 0.032 & 2 & $* * *$ \\
\hline Q27Phys_c & My [physics] teacher sees me as a [physics] person & 1.027 & 0.027 & 0 & 1.630 & 0.032 & 2 & $* * *$ \\
\hline Q27Phys_d & I am interested in learning more about [physics] & 1.250 & 0.028 & 1 & 1.854 & 0.034 & 2 & $* * *$ \\
\hline Q27Phys_g & I enjoy learning [physics] & 1.254 & 0.028 & 1 & 1.893 & 0.033 & 2 & $* * *$ \\
\hline Q27Phys_e & $\begin{array}{l}\text { I am confident that I can understand [physics] } \\
\text { in class }\end{array}$ & 1.526 & 0.029 & 1 & 2.180 & 0.032 & 2 & $* * *$ \\
\hline Q27Phys_f & $\begin{array}{l}\text { I am confident that I can understand [physics] } \\
\text { outside of class }\end{array}$ & 1.304 & 0.027 & 1 & 2.037 & 0.032 & 2 & $* * *$ \\
\hline Q27Phys_h & I can do well on exams in [physics] & 1.453 & 0.028 & 1 & 2.074 & 0.031 & 2 & $* * *$ \\
\hline Q27Phys_i & I understand concepts I have studied in [physics] & 1.450 & 0.029 & 1 & 2.077 & 0.032 & 2 & $* * *$ \\
\hline Q27Phys_j & Others ask me for help in [physics] & 1.156 & 0.028 & 2 & 1.713 & 0.033 & 2 & $* * *$ \\
\hline Q27Phys_n & I can overcome setbacks in [physics] & 1.777 & 0.028 & 2 & 2.153 & 0.030 & 2 & $* * *$ \\
\hline
\end{tabular}


TABLE III. Wilcoxon test for physics career item. $* * *: p<0.001$.

\begin{tabular}{|c|c|c|c|c|c|c|c|c|}
\hline \multirow[b]{2}{*}{ Item } & \multirow[b]{2}{*}{ Item Description } & \multicolumn{3}{|c|}{ Female } & \multicolumn{3}{|c|}{ Male } & \multirow[b]{2}{*}{$\mathrm{Sig}$} \\
\hline & & Mean & SE & Median & Mean & SE & $\overline{\text { Median }}$ & \\
\hline Q3e & $\begin{array}{l}\text { Please rate the current likelihood } \\
\text { of your choosing a career in [physics] }\end{array}$ & 0.528 & 0.018 & 0 & 0.819 & 0.023 & 0 & $* * *$ \\
\hline
\end{tabular}

the OCSE activities items were left as ordinal values with 0 corresponding to never in my life and 4 corresponding to more than 6 times in my life. These responses were converted to have units of number of times for the confirmatory factor analysis (CFA) and structural equation model (SEM) with 1-2 times set to 1.5, 3-4 times set to 3.5, and so on. However, the type of variable these items were treated as did not affect the results of the SEM. We present the results with the linearized variables because they are easier to interpret. The physics identity items asked students to respond on a scale of "0-Strongly Disagree" to "4-Strongly Agree." The item "I see myself as a [physics] person" was used as an overall indicator of physics identity, similar to other work [8]. Finally, the physics career intentions item asked students to "Please rate the current likelihood of your choosing a career in [physics]" on an anchored scale of "0-Not at all Likely" to "4-Extremely Likely." Participants indicated gender by responding to the question, "What is your gender?" The options were "Female" and "Male."

To determine the relationship between participating in OCSE activities, physics identity dimensions, the overall indicator of physics identity, and physics career choice, we first conducted a confirmatory factor analysis of the physics identity items and the OCSE factor. We then built and tested a structural equation model. To assess for gender differences, we performed a multigroup analysis, thus determining if there were significant differences in the paths of the model for females and for males.

\section{B. Measurement model}

All analysis was conducted in $\mathrm{R}$ version 3.1.0 using the lavaan package $[29,30]$. Exploratory factor analysis was previously conducted on the physics identity items on the SaGE survey, showing that the 10 physics identity items form three factors: interest, performance/competence beliefs, and recognition beliefs $[9,24]$. This is consistent with the findings from the earlier PRiSE survey [7]. As the primary goal of the current analysis is determining the impact of OCSE activities on physics identity, an OCSE activity factor was also created by combining individual responses, to provide an index of students' level of experience with these activities. We then performed a confirmatory factor analysis (CFA) that included the three identity dimensions and OCSE activities. Factor analysis establishes whether indicator variables measure latent (underlying) variables. We used the full information maximum likelihood (FIML) method to handle missing data [31].

In order to assess the model fit, we computed the comparative fit index (CFI), the Tucker-Lewis index (TLI), also known as the non-normed fit index (NNFI), and the root mean square of approximation (RMSEA) [32]. We use these fit indices rather than a chi-squared test because the latter does not give meaningful results when dealing with large samples [33]. The other fit indices scale well for large samples. Additionally, reporting on multiple fit indices is more robust than choosing a single one to compute [31]. We assessed each of the factors by calculating the construct reliability and the average variance extracted (AVE) [31,34]. Construct reliability represents whether the items are consistent with each other in measuring the intended latent variable, while AVE represents how much of the variance in the items can be explained with the latent variable. We assessed discriminant validity by comparing the AVE for all factors overall to the covariance between factors [31]. Discriminant validity must be assessed to determine if the factors are distinct.

\section{Structural equation model}

SEM is a useful tool for understanding the relationships between factors, combining CFA and multiple regression [31]. A schematic of our SEM is shown in Fig. 1. This model mimics the previously found relationships between mathematics identity dimensions and overall mathematics identity for college students [26] but adds the relationship between identity and career choice and also the influence of OCSE activities on each physics identity dimension [7]. We sought to determine to what extent each identity dimension was predicted by OCSE activities. Furthermore, similar to the mathematics identity model, the effect of performance/competence beliefs on physics identity is mediated by recognition beliefs and interest. As with the CFA, missing data was accounted for using the FIML method [31]. The model was tested for all students using a multigroup analysis to determine whether there are statistical differences between the models for males and females. To perform the multigroup analysis, we used model invariance tests [32]. In the baseline model, the path estimates for the male and female models were allowed to vary freely. Then, we restricted the factor loadings to be equal in the two models. Examination of the modification indices for each loading revealed 


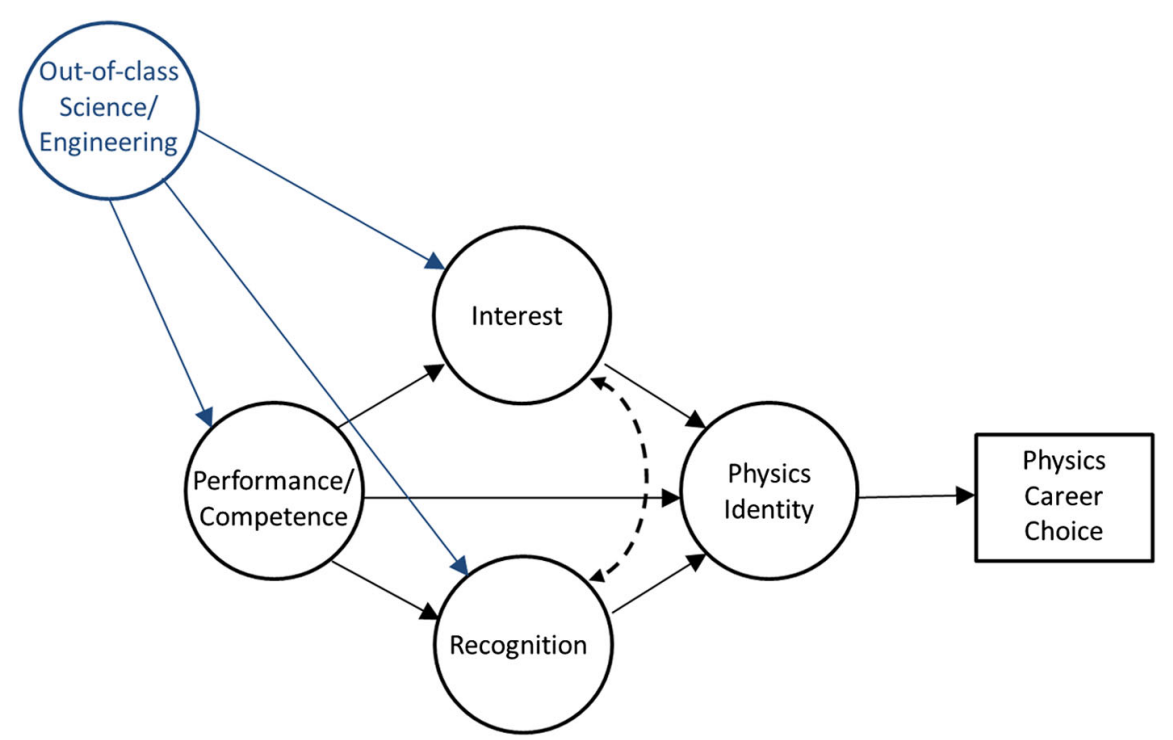

FIG. 1. Proposed structural model for the SEM analysis of the relationships between the identity dimensions, physics career choice, and out-of-class science and engineering activities.

whether there was a significant difference between the models for males and for females. Modification indices greater than 3.841 indicate a significant chi-squared difference with the model when the path estimate is allowed to vary freely. If factor loadings are different, this indicates that the factor is defined somewhat differently for the two groups. We then repeated this process constraining both the factor loadings and regression paths to be equal to determine which regression paths differed between models. In the final model, all factor loadings are constrained to be equal for males and females, but only regression paths that were found to have nonstatistically significant differences were constrained to be equal. This method ensures that the factors have a consistent definition across models for the two groups, and interpretation focuses on the differences in relationships between factors rather than on differences in

TABLE IV. Confirmatory factor analysis $(N=5988)$.

\begin{tabular}{|c|c|c|c|c|c|c|}
\hline Latent variable & $\begin{array}{l}\text { Indicator } \\
\text { variable }\end{array}$ & $\begin{array}{l}\text { Standardized factor } \\
\text { loading }\end{array}$ & $\begin{array}{l}\text { Standard } \\
\text { error }\end{array}$ & $\begin{array}{c}\text { Item reliability } \\
\left(r^{2}\right)\end{array}$ & $\begin{array}{l}\text { Construct } \\
\text { reliability }\end{array}$ & $\begin{array}{l}\text { Average variance } \\
\text { extracted }\end{array}$ \\
\hline \multirow{7}{*}{$\begin{array}{l}\text { Out-of-class science and } \\
\text { engineering activities }\end{array}$} & & & & & 0.832 & 0.455 \\
\hline & Q21a & 0.557 & 0.026 & 0.310 & & \\
\hline & Q21d & 0.719 & 0.030 & 0.517 & & \\
\hline & Q21e & 0.638 & 0.038 & 0.407 & & \\
\hline & Q21g & 0.668 & 0.030 & 0.446 & & \\
\hline & Q21h & 0.686 & 0.024 & 0.471 & & \\
\hline & Q21i & 0.762 & 0.034 & 0.581 & & \\
\hline \multirow[t]{3}{*}{ Recognition } & & & & & 0.892 & 0.805 \\
\hline & Q27Phys_b & 0.88 & 0.016 & 0.774 & & \\
\hline & Q27Phys_c & 0.914 & 0.016 & 0.835 & & \\
\hline \multirow{3}{*}{ Interest } & & & & & 0.889 & 0.800 \\
\hline & Q27Phys_d & 0.872 & 0.017 & 0.760 & & \\
\hline & Q27Phys_g & 0.916 & 0.016 & 0.839 & & \\
\hline \multirow[t]{7}{*}{ Performance/competence } & & & & & 0.940 & 0.723 \\
\hline & Q27Phys_e & 0.890 & 0.016 & 0.792 & & \\
\hline & Q27Phys_f & 0.880 & 0.016 & 0.774 & & \\
\hline & Q27Phys_h & 0.903 & 0.016 & 0.815 & & \\
\hline & Q27Phys_i & 0.918 & 0.016 & 0.843 & & \\
\hline & Q27Phys_j & 0.784 & 0.018 & 0.615 & & \\
\hline & Q27Phys_n & 0.707 & 0.017 & 0.500 & & \\
\hline
\end{tabular}


what the factors mean. Model fit was assessed with the CFI, TLI, and the RMSEA, similarly to the CFA [32]. We also calculated the chi-squared for each group though this was not expected to be meaningful given the large sample size [33].

\section{RESULTS}

\section{A. Measurement model}

The results of the CFA are shown in Table IV. The chisquared was 2423 and was significant. However, as mentioned, this is to be expected for a large sample size [33]. The CFI was 0.96, and the TLI (NNFI) was 0.95 . A good fit is indicated by a CFI or TLI $\geq 0.95$ [32]. The RMSEA was 0.06. A good fit is indicated by an RMSEA of $<0.06$, and a poor fit is indicated by an RMSEA of $>0.10$ [32]. This is a good fit according the CFI and TLI and an acceptable fit according to the RMSEA. Factor loadings are standardized and are all $>0.50$ indicating that all items are good or better measures of the factor [32]. Construct reliability was found to be greater than 0.80 and is in the acceptable range [34]. The AVE for each factor was found to be $>0.70$ for all physics identity factors indicating convergent validity [35]. The AVE for OCSE activities is near the suggested cutoff for convergent reliability of 0.50 [35]. Given the importance of theory in CFA and SEM, this AVE is sufficient [36]. The square root of the AVE for all factors overall is larger than the covariance between factors overall indicating discriminant validity [31].

\section{B. Structural equation model}

The fitted SEM for all students is shown in Fig. 2 and the loadings are shown in Table V. There were 238 missing patterns in the male group and 291 missing patterns in the female group. The final sample size was 2509 for males and 3032 for females. The chi-square for this model was 1373 for the male group and 1633 for the female group, both of which are significant. The CFI was 0.95 , and the TLI was 0.95 . Both of these fit indices indicate a good fit with values $\geq 0.95$ [32]. The RMSEA was 0.06 indicating an acceptable fit [32]. All paths shown are significant at the $p<0.001$ level. Factor loadings are shown in Table $\mathrm{V}$, showing all factor loadings were constrained to be equal, and that the only regression paths that were not statistically different were paths 17 , 19, and 20. All other regression paths differed significantly between the male and female groups.

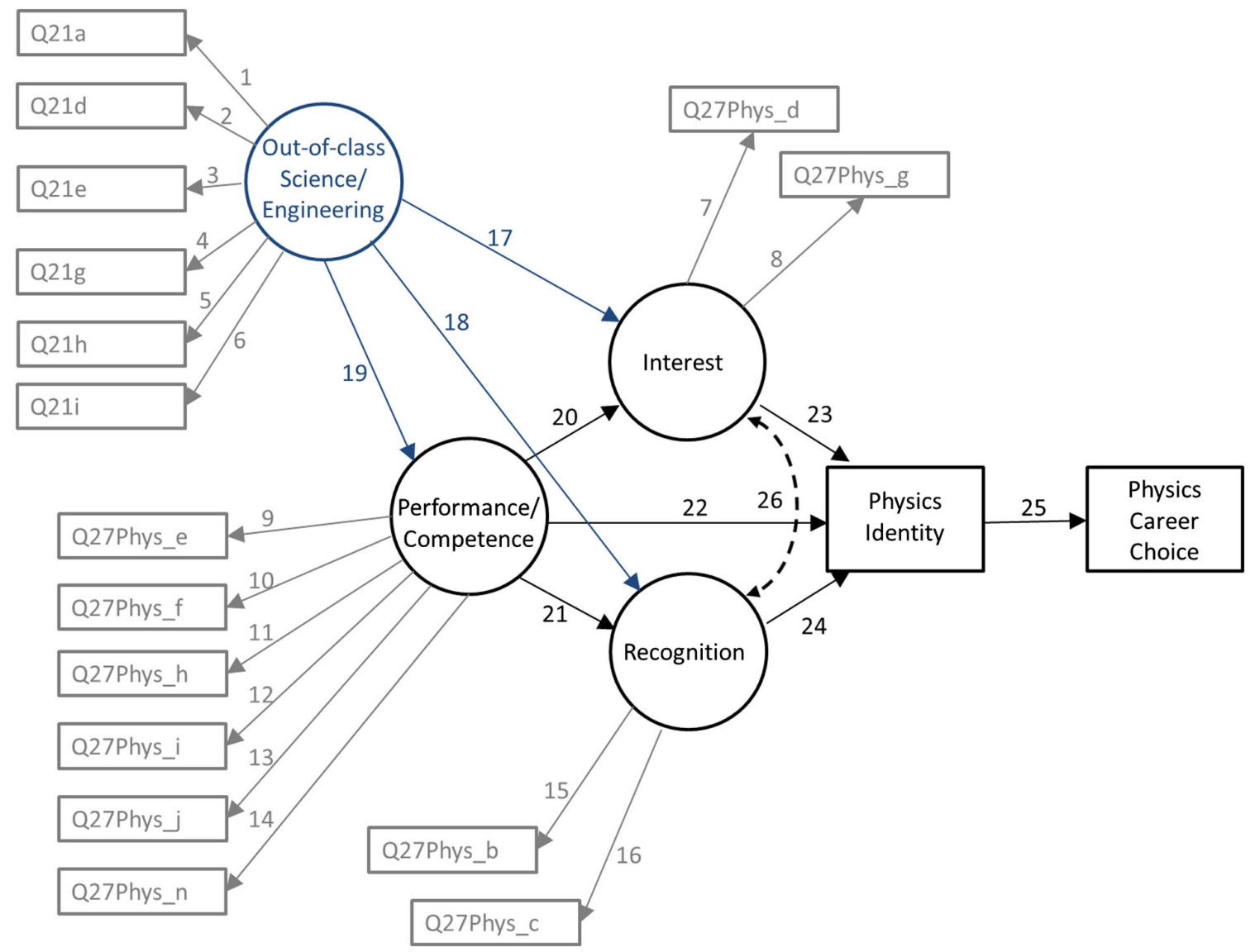

FIG. 2. Structural equation model of the relationships between the identity dimensions, physics career choice, and out-of-class science and engineering activities. Boxes indicate survey items, and circles represent latent variables (factors). 
TABLE V. Factor and regression loadings for SEM. All paths are significant at the $p<0.001$ level unless otherwise noted. $* *$ indicates $p<0.01$. $(=)$ indicates that the path was constrained equal between groups. $(N=5541)$.

\begin{tabular}{|c|c|c|c|c|c|c|}
\hline \multirow[b]{2}{*}{ Label } & \multicolumn{3}{|c|}{ Female } & \multicolumn{3}{|c|}{ Male } \\
\hline & Est. & SE & Std. coeff. & Est. & SE & Std. coeff. \\
\hline \multicolumn{7}{|c|}{ Factor loadings } \\
\hline 1 & 1.075 & 0.027 & 0.593 & $(=)$ & & 0.531 \\
\hline 2 & 1.597 & 0.031 & 0.747 & $(=)$ & & 0.644 \\
\hline 3 & 1.827 & 0.04 & 0.646 & $(=)$ & & 0.607 \\
\hline 4 & 1.594 & 0.032 & 0.691 & $(=)$ & & 0.653 \\
\hline 5 & 1.227 & 0.025 & 0.718 & $(=)$ & & 0.617 \\
\hline 6 & 2.033 & 0.035 & 0.776 & $(=)$ & & 0.723 \\
\hline 7 & 0.551 & 0.013 & 0.873 & $(=)$ & & 0.861 \\
\hline 8 & 0.559 & 0.013 & 0.912 & $(=)$ & & 0.901 \\
\hline 9 & 1.109 & 0.016 & 0.889 & $(=)$ & & 0.881 \\
\hline 10 & 1.081 & 0.016 & 0.878 & $(=)$ & & 0.867 \\
\hline 11 & 1.106 & 0.015 & 0.898 & $(=)$ & & 0.899 \\
\hline 12 & 1.136 & 0.015 & 0.915 & $(=)$ & & 0.915 \\
\hline 13 & 0.972 & 0.017 & 0.786 & $(=)$ & & 0.757 \\
\hline 14 & 0.848 & 0.017 & 0.687 & $(=)$ & & 0.722 \\
\hline 15 & 0.691 & 0.013 & 0.903 & $(=)$ & & 0.890 \\
\hline 16 & 0.691 & 0.012 & 0.883 & $(=)$ & & 0.884 \\
\hline \multicolumn{7}{|c|}{ Regressions } \\
\hline 17 & 0.187 & 0.026 & 0.084 & $(=)$ & & 0.084 \\
\hline 18 & $0.088 * *$ & 0.029 & 0.054 & 0.182 & 0.031 & 0.105 \\
\hline 19 & 0.438 & 0.019 & 0.401 & $(=)$ & & 0.401 \\
\hline 20 & 1.743 & 0.050 & 0.856 & $(=)$ & & 0.856 \\
\hline 21 & 1.159 & 0.035 & 0.770 & 1.223 & 0.038 & 0.770 \\
\hline 22 & $-0.103 * *$ & 0.034 & -0.092 & $-0.116^{* *}$ & 0.042 & -0.092 \\
\hline 23 & 0.100 & 0.023 & 0.181 & 0.183 & 0.028 & 0.295 \\
\hline 24 & 0.623 & 0.022 & 0.833 & 0.567 & 0.027 & 0.715 \\
\hline 25 & 0.340 & 0.015 & 0.424 & 0.402 & 0.016 & 0.481 \\
\hline \multicolumn{7}{|c|}{ Covariances } \\
\hline 26 & 0.541 & 0.022 & 0.541 & $(=)$ & & 0.541 \\
\hline
\end{tabular}

\section{DISCUSSION}

Table I shows that men report engaging in OCSE activities to a greater extent than women do, and this difference is significant at the $p<0.001$ level. This is true for each item including within both programmed $(\mathrm{Q} 21 \mathrm{a}$, Q21g, Q21h) and everyday settings (Q21d, Q21e, Q21i). This is in contrast to prior results that found men and women participated in STEM programmed settings at similar rates $[15,21]$. This discrepancy may arise because the prior work focused on science and math programs and did not include engineering. Activities in programmed settings have been found to impact men and women equally in terms of STEM career interests [15]. Women participating in activities that may lead to physics identity development and career choice less frequently may lead to fewer women pursuing physics careers compared to men. Furthermore, Table II shows that males respond higher on all physics identity items. The difference in men's and women's performance/competence beliefs is larger than can be accounted for by any small differences in measured performance [37-40]. These differences are also significant at the $p<0.001$ level. Finally, Table III shows that men are significantly more likely to pursue physics careers.

The CFA model is a good fit indicating that each of the factors measures the intended construct. Additionally, the factors represent the distinct constructs of OCSE activities, recognition beliefs, interest, and performance/competence beliefs. The SEM reveals the relationships between the factors. The physics identity dimensions are related to each other in the same manner as the math identity dimensions are, indicating that this model for discipline-specific identity for general populations of students is likely to apply to other fields as well [26]. The overall indicator of physics identity predicts physics career choice. Recognition beliefs and interest both positively predict physics identity, however performance/competence beliefs on its own negatively predicts physics career choice. This may be surprising at first 
glance. However, performance/competence beliefs positively predict both recognition beliefs and interest. The effect of performance/competence beliefs are mediated by recognition beliefs and interest, meaning that if performance/competence beliefs are developed in isolation from recognition beliefs and interest, a student is not more likely to develop an overall physics identity. While the direct effect is negative, it is relatively small. Also of note is the dominant role of recognition beliefs. The effect size of recognition beliefs on physics identity is much larger than that of interest on physics identity, underscoring the key role that recognition beliefs play in identity development and career choice.

There are several key gender differences in the relationships between the identity dimensions, overall identity, and physics career choice. The only regression estimate that does not depend on gender is in the effect of performance/ competence beliefs on interest. Recognition beliefs, while having the largest impact on overall identity for both men and women, dominate even more over interest in the SEM for the female group. This emphasizes how important recognition beliefs are for women and is consistent with prior work [9]. Similarly, the effect of interest on overall identity is larger for men than for women. Furthermore, overall physics identity has a larger effect on career choice for men than women. So, not only do women have lower physics identities overall, but their physics identities have less impact on their career choice.

The three paths between OCSE activities and each of the identity dimensions are all significant for both men and women with OCSE activities having a larger effect on performance/competence beliefs than on either recognition beliefs or interest. This is concerning given that performance/competence beliefs do not directly impact physics identity. The path coefficients to performance/competence beliefs and interest are the same for men and women. However, the impact of OCSE activities on recognition beliefs is larger for men than for women. Furthermore, this path is only significant at the $p<0.01$ level for women rather than at the $p<0.001$ level for men. Given the importance of recognition beliefs on physics identity and career choice for women, this indicates that OCSE activities may not accomplish what is needed for women to develop physics identities and enter physics careers even though previous work has found that they do increase STEM career interest in general [15].

\section{CONCLUSION}

In summary, we conducted a confirmatory factor analysis of the three physics identity dimensions along with OCSE activities. Subsequently, we developed a structural equation model showing the relationships of the individual physics identity dimensions to each other and to overall physics identity and in turn physics career intentions. Furthermore, we modeled the effect of OCSE activities on each of the identity dimensions. We found that interest and recognition beliefs directly contribute to overall physics identity, but performance/competence beliefs only have a positive effect when mediated through interest and recognition beliefs, consistent with the math identity model [26]. This consistency suggests that other discipline-based identities can be modeled similarly. Recognition beliefs were found to have the largest impact on overall physics identity, while OCSE activities were found to have the largest impact on the performance/competence beliefs dimension of identity indicating that OCSE activities do not emphasize the most necessary identity dimensions for physics identity development and increasing physics career intentions. Furthermore, OCSE activities do not support increasing the representation of women in physics. Recognition beliefs are significantly more important for women as compared to men in terms of developing a physics identity [9]. However, OCSE activities have a smaller effect on women's than on men's recognition. Finally, men were found to report participating in OCSE activities to a greater extent than women both in programmed settings and everyday activities.

Though the out-of-class activities items are for science and engineering in general rather than for physics specifically, the impact on performance/competence beliefs is large, indicating that there is a strong connection between OCSE activities in general and physics identity. While the results may be different for physics specific out-of-class activities, such activities are rare at the high school level. Emphasizing recognition beliefs is of key importance in OCSE activities and may be related to increasing opportunities for students to acquire agency with physics and become interested in physics careers $[9,18,20]$. Modifying programmed activities to better support recognition beliefs and interest is more practical than modifying everyday activities because everyday activities are generally more removed from the influence of school. However, educators can engage in discussions with parents about encouraging their children as parents are more likely to be aware of and involved in their children's everyday activities. For example, the finding that parents will give more detailed science explanations to boys than to girls [13] may communicate to girls that their parents view helping them become better at science as less worthwhile. Educators can discuss with parents the influence their behaviors may have on girls in physics especially if their child doubts their own capabilities. When planning OCSE activities, care must be taken to ensure that students, particularly women, are recognized as physics people. Based on the forms that recognition takes in high school classrooms [25], recognizing students in programmed OCSE activities translates to ensuring that activities are not only fun and engaging but also provide challenge. Students need to be provided with sufficient guiding support in these activities. 
This applies to summer programs, clubs, and competitions such as science fairs. Facilitators of OCSE activities should be trained in how to facilitate group activities so that students are receiving recognition both from the facilitators themselves and other students. More work is needed to determine the optimal method for improving programmed activities to better support engagement in physics and subsequently increasing the number of physics majors and the percentage of physics majors who are women.

\section{ACKNOWLEDGMENTS}

The authors thank the National Science Foundation (NSF GSE 1036617) for funding of the Sustainability and Gender in Engineering (SaGE) project.
[1] National Academy of Sciences, National Academy of Engineering, and Institute of Medicine, Rising Above the Gathering Storm, Revisited (The National Academies Press, Washington, DC, 2010), https://doi.org/10.17226/ 12999.

[2] J. L. Bromberg, The birth of the laser, Phys. Today 41, 26 (1988).

[3] Physics for an advanced world, Institute of Physics, London, 2009.

[4] S. Nicholson and P. J. Mulvey, Roster of Physics Departments with Enrollment and Degree Data, 2017 (AIP Statistical Research Center, College Park, MD, 2018).

[5] Table 322.10. Bachelor's degrees conferred by postsecondary institutions, by field of study: Selected years, 197071 through 2015-16, National Center for Education Statistics, Retrieved 2019. https://nces.ed.gov/programs/ digest/d17/tables/dt17_322.10.asp.

[6] A. M. Porter and R. Ivie, Women in Physics and Astronomy, 2019 (AIP Statistical Research Center, College Park, MD, 2019).

[7] Z. Hazari, G. Sonnert, P. M. Sadler, and M.-C. Shanahan, Connecting high school physics experiences, outcome expectations, physics identity, and physics career choice: A gender study, J. Res. Sci. Teach. 47, 978 (2010).

[8] A. Godwin, G. Potvin, Z. Hazari, and R. Lock, Identity, critical agency, and engineering: An affective model for predicting engineering as a career choice, J. Eng. Educ. 105, 312 (2016).

[9] R. M. Lock, Z. Hazari, and G. Potvin, Physics career intentions: The effect of physics identity, math identity, and gender, AIP Conf. Proc. 1513, 262 (2013).

[10] R. M. Lock, J. Castillo, Z. Hazari, and G. Potvin, Determining strategies that predict physics identity: Emphasizing recognition and interest, in Proceedings of the 2015 Physics Education Research Conference, College Park, $M D$, edited by A. D. Churukian, D. L. Jones, and L. Ding (AIP, New York, 2015).

[11] P. Bell, B. Lewenstein, A. W. Shouse, and M. A. Feder, Science learning in designed settings, in Learning Science in Informal Environments: People, Places, and Pursuits (The National Academies Press, Washington, DC, 2009), https:// doi.org/10.17226/12190.

[12] A. Sahin, STEM clubs and science fair competitions: Effects on post-secondary matriculation, J. STEM Educ. 14, 5 (2013).
[13] T. V. Abernathy and R. N. Vineyard, Academic competitions in science: What are the rewards for students?, Clear. House J. Ed. Strat. Iss. Id. 74, 269 (2001).

[14] C. M. Czerniak and A. T. Lumpe, Predictors of science fair participation using the theory of planned behavior, School Sci. Math. 96, 355 (1996).

[15] K. P. Dabney, R. H. Tai, J. T. Almarode, J. L. MillerFriedmann, G. Sonnert, P. M. Sadler, and Z. Hazari, Out-of-school time science activities and their association with career interest in STEM, Int. J. Sci. Educ. Part B. 2, 63 (2012).

[16] J. E. Stake and K. R. Mares, Evaluating the impact of science-enrichment programs on adolescents' science motivation and confidence: The splashdown effect, J. Res. Sci. Teach. 42, 359 (2005).

[17] H. L. Gibson and C. Chase, Longitudinal impact of an inquiry-based science program on middle school students' attitudes toward science, Sci. Educ. 86, 693 (2002).

[18] S. J. Basu, A. Calabrese Barton, N. Clairmont, and D. Locke, Developing a framework for critical science agency through case study in a conceptual physics context, Cult. Stud. Sci. Educ. 4, 345 (2009).

[19] J. R. DeLisi, J. Fuccillo Kook, E. Fields, A. Jurist Levy, and M. Pasquale, Approaches for conducting middle school science fairs: A landscape study, in Proceedings of the 2018 Annual Meeting of the American Educational Research Association, Retrieved from the AERA Online Paper Repository (American Educational Research Association, Washington, DC, 2018).

[20] R. Elmesky, Rap as a roadway: Creating creolized forms of science in an era of cultural globalization, Cult. Stud. Sci. Educ. 6, 49 (2011).

[21] S. D. Simpkins, P. E. Davis-Kean, and J. S. Eccles, Math and science motivation: A longitudinal examination of the links between choices and beliefs, Dev. Psychol. 42, 70 (2006).

[22] A. V. Maltese and R. H. Tai, Eyeballs in the fridge: Sources of early interest in science, Int. J. Sci. Educ. 32, 669(2010).

[23] H. B. Carlone and A. Johnson, Understanding the science experiences of successful women of color: Science identity as an analytic lens, J. Res. Sci. Teach. 44, 1187 (2007).

[24] G. Potvin and Z. Hazari, The development and measurement of identity across the physical sciences, in Proceedings of the 2013 Physics Education Research Conference, Portland, OR, edited by P. V. Engelhardt, A. D. Churukian, and D. L. Jones (AIP, New York, 2013). 
[25] Z. Hazari and C. Cass, Towards meaningful physics recognition: What does this recognition actually look like?, Phys. Teach. 56, 442 (2018).

[26] J. D. Cribbs, Z. Hazari, G. Sonnert, and P. M. Sadler, Establishing an explanatory model for mathematics identity, Child Development 86, 1048 (2015).

[27] P. J. Burke, Introduction, in Advances in Identity Theory and Research, edited by P. J. Burke, T. J. Owens, R. Serpe, and P. A. Thoits (Kluwer, New York, NY, 2003), pp. 1-7.

[28] L. Klotz, G. Potvin, A. Godwin, J. Cribbs, Z. Hazari, and N. Barclay, Sustainability as a route to broadening participation in engineering, J. Engin. Educ. 103, 137 (2014).

[29] R Core Team, R: A language and environment for statistical computing, R Foundation for Statistical Computing, Vienna, Austria, 2013. http://www.r-project.org/.

[30] Y. Rosseel, lavaan: An R package for structural equation modeling, J. Stat. Softw. 48, 1 (2012).

[31] J. B. Schreiber, A. Nora, F. K. Stage, E. A. Barlow, and J. King, Reporting structural equation modeling and confirmatory factor analysis results: A review, J. Educ. Res. 99, 323 (2006).

[32] B. G. Tabachnik and L. S. Fidell, Using Multivariate Statistics, 5th ed. (Pearson Education, Inc., Boston, 2007).
[33] R. E. Schumacker and R. G. Lomax, A Beginner's Guide to Structural Equation Modeling, 3rd ed. (Routledge, New York, NY, 2010).

[34] J. F. Hair Jr., W. C. Black, B. J. Babin, and R. E. Anderson, Multivariate Data Analysis, 5th ed. (Prentice Hall, Upper Saddle River, NJ, 1998).

[35] W. R. Dillon and M. Goldstein, Multivariate Analysis: Methods and Applications (Wiley, New York, NY, 1984).

[36] D. Borsboom, G. J. Mellenbergh, and J. Van Heerden, The concept of validity, Psychol. Rev. 111, 1061 (2004).

[37] J. S. Hyde and M. C. Linn, Diversity. Gender similarities in mathematics and science, Science 314, 599 (2006).

[38] Z. Hazari, R. H. Tai, and P. M. Sadler, Gender differences in introductory university physics performance: The influence of high school physics preparation, Sci. Educ. 91, 847 (2007).

[39] R. H. Tai and P. M. Sadler, Gender differences in introductory undergraduate physics performance: University physics versus college physics in the USA, Int. J. Sci. Educ. 23, 1017 (2001).

[40] J. Docktor and K. Heller, Gender differences in both force concept inventory and introductory physics performance, AIP Conf. Proc. 1064, 15 (2008). 